\title{
Diário de Campo e a Relação do(a) Pesquisador(a) com o Campo-Tema na
}

\section{Pesquisa-Intervenção}

\author{
Renata Fischer da Silveira Kroeff* \\ Universidade Federal do Rio Grande do Sul, Porto Alegre, RS, Brasil \\ ORCID: https://orcid.org/0000-0002-9029-6647 \\ Póti Quartiero Gavillon** \\ Universidade Federal do Rio Grande do Sul, Porto Alegre, RS, Brasil \\ ORCID: https://orcid.org/0000-0002-4118-784X \\ Laís Vargas Ramm*** \\ Universidade Federal do Rio Grande do Sul, Porto Alegre, RS, Brasil \\ ORCID: https://orcid.org/0000-0003-0716-4377
}

\section{RESUMO}

O presente trabalho aborda a relação do(a) pesquisador(a) com o campo-tema, desfazendo a sobreposição entre campo e espaço geográfico, para refletir sobre o papel do uso de diários de campo na pesquisa-intervenção. A partir da abordagem enativa da cognição, tomamos a noção de afeto como elemento modulador da atenção do(a) pesquisador(a), que se relaciona com a problemática da pesquisa, produzindo registros de aspectos do cotidiano e de suas implicações no diário, que passam a ser percebidos como parte do campo-tema da pesquisa. Tomamos como objeto de análise diários de campo escritos por pesquisadores(as) em uma pesquisa que buscava acompanhar processos de aprendizagem com um jogo digital de localização. Concluímos que o uso do diário de campo acompanha e participa da produção da atenção do(a) pesquisador(a) na sua inserção no campo-tema, de modo que as memórias, hábitos e a inserção do(a) pesquisador(a) nos contextos cotidianos também compõem a pesquisa, tomada como um fazer político que intervém na realidade.

Palavras-chave: diário, pesquisa-intervenção, pesquisa qualitativa, metodologia, pesquisa de campo.

\section{Field Diary and the Researcher's Relationship with the Theme-Field in}

\section{Intervention Research}

\begin{abstract}
This paper discusses the relationship of the researcher with the theme-field, undoing the overlap between field and geographical space, to reflect on the role of the use of field diaries in intervention research. From the enactive approach to cognition, we take the notion of affect as a modulating element of the researcher's attention, which is related to the research problem,
\end{abstract}


producing records of everyday aspects and their implications in the diary, which come to be perceived as part of the research theme-field. We took as object of analysis field diaries written by researchers in a research that sought to follow learning processes with a digital location-based game. We conclude that the use of the field diary accompanies and participates in the production of the researcher's attention in their participation in the theme-field, so that the researcher's memories, habits and participation of everyday contexts also make up the research, taken as a political action that intervenes in reality.

Keywords: diary, intervention research, qualitative research, methodology, field research.

\section{Diario de campo y la relación del(a) investigador(a) con el campo-tema en}

\section{la investigación-intervención}

\section{RESUMEN}

Este artículo trata de la relación del(a) investigador(a) con el campo-tema, deshaciendo la superposición entre campo y espacio geográfico, para reflexionar sobre el papel del uso de diarios de campo en la investigación-intervención. Desde el enfoque enactivo a la cognición, tomamos la noción de afecto como un elemento modulador de la atención del(a) investigador(a), que se relaciona con el problema de investigación, produciendo registros de aspectos del cotidiano y de sus implicaciones en el diario, los cuales pasan a ser percibidos como parte del campo-tema de investigación. Tomamos como objeto de análisis diarios de campo escritos por investigadores(as) en una investigación que buscaba seguir los procesos de aprendizaje con un juego digital de localización. Concluimos que el uso del diario de campo acompaña y participa en la producción de la atención del(a) investigador(a) en su inserción en el campo-tema, de modo que las memorias, los hábitos y la inserción del(a) investigador(a) en los contextos cotidianos también componen la investigación, tomada como una acción política que interviene en la realidad.

Palabras clave: diario, investigación-intervención, investigación cualitativa, metodología, investigación de campo.

O trabalho de campo é uma estratégia importante de pesquisa, uma vez que envolve a articulação de proposições teóricas com a experiência empírica na produção de saberes contextualizados. Frequentemente, em estudos exploratórios com viés qualitativo desenvolvidos na antropologia, na psicologia e em outras áreas de conhecimento utiliza-se a escrita de diários de campo como ferramenta metodológica para registro e posterior análise da experiência do(a) pesquisador(a) e dos(as) participantes.

Pezzato e L'abbate (2011) afirmam que pesquisas que priorizam o trabalho de campo e a observação participante começaram a ser mais utilizadas a partir do trabalho Os Argonautas 
do Pacífico Ocidental, de Bronislaw Malinowski, do início do século XX. Segundo as autoras, o diário de campo se difunde como ferramenta de pesquisa a partir do trabalho de Malinowski, por meio da etnografia, que metodologicamente propõe um afastamento daquilo que se observa com uma grande quantidade de anotações de cunho descritivo.

Outras estratégias de pesquisa contemporâneas e com uma perspectiva pósestruturalista, como a pesquisa-intervenção, utilizam-se da escrita de diários de campo numa direção oposta, colocando em primeiro plano a relação entre pesquisador(a) e campo de pesquisa, em uma abordagem que compreende uma atuação assumidamente implicada e não mais neutra. Esta metodologia de pesquisa-intervenção tem forte influência do movimento institucionalista (Rocha \& Aguiar, 2003), iniciado na França, na década de sessenta. Tal movimento tinha como um de seus objetivos problematizar as instituições como práticas de regulação da vida e produtoras de subjetividade. Entre as instituições discutidas estava a própria ciência moderna e seus princípios de verdade e neutralidade. Propondo que toda pesquisa é uma ação política desde a escolha de sua temática até a divulgação de seus resultados, a metodologia de pesquisa-intervenção se consolida na contracorrente da noção moderna de ciência. Por política nos referimos a toda ação humana que coloca em relação sujeitos e instituições, segundo regras ou normas não necessariamente jurídicas ou legais (Passos \& Barros, 2012). Ou seja, a pesquisa é política porque produz formas de organização dos coletivos, compreendendo seus posicionamentos em relação à produção de experiências de vida em sociedade.

$\mathrm{Na}$ pesquisa-intervenção, a relação entre pesquisador(a), participantes e fenômeno pesquisado transforma-se em um aspecto crucial da produção de conhecimento, uma vez que determina os próprios caminhos da pesquisa (Aguiar \& Rocha, 1997). A utilização de diários de campo como ferramenta de pesquisa possibilita visibilizar aspectos da implicação do(a) pesquisador(a) com o campo estudado. Tal modalidade de escrita compreende a descrição dos procedimentos do estudo, do desenvolvimento das atividades realizadas e também de possíveis alterações realizadas ao longo do percurso da pesquisa, além de servir como uma narrativa textual das impressões do(a) pesquisador(a). No diário se traz para o debate os conhecimentos e saberes dos(as) pesquisadores(as), propostas e ações, suas angústias, desejos, avanços e dificuldades (Pezzato \& L'abbate, 2011). Desta forma, o diário de campo também se constitui como ferramenta de intervenção ao provocar reflexões sobre a própria prática de pesquisa e das decisões em relação ao planejamento, desenvolvimento, método de análise e divulgação científica. 
Oliveira (2014) destaca a importância do diário como registro, mesmo quando se trata de entrevistas gravadas, pois o diário registraria sutilezas que apenas a transcrição da entrevista não daria conta, como a percepção de expressões de emoção. A atenção do(a) pesquisador(a) à própria experiência e ao movimento dos(as) participantes é entendida como uma fonte importante da pesquisa (Kastrup, 2012). Compreendendo a descrição dos processos observados e as impressões do(a) pesquisador(a), a escrita dos diários de campo pode envolver registros que permitam acompanhar o movimento da atenção do(a) pesquisador(a) em relação aos fenômenos estudados.

Na pesquisa-intervenção de viés cartográfico (Passos, Kastrup, \& Escóssia, 2012), a compreensão a respeito dos dados de uma pesquisa é de que os mesmos são produzidos e não extraídos de uma realidade independente do(a) observador(a). Neste sentido, a modulação da atenção do(a) pesquisador(a) tem significativa relevância, uma vez que constitui processualmente o problema de pesquisa e os desdobramentos explicativos produzidos na relação com o campo. Kastrup (2012) sugere que uma atitude atencional aberta permite ao(à) pesquisador(a) mudar o foco da pesquisa e perceber elementos diferentes. O papel da escrita de diários de campo, neste sentido, auxilia a produzir e acompanhar essa atitude atencional aberta, ao mesmo tempo que amplia a presença da pesquisa no cotidiano do(a) pesquisador(a). A escrita e leitura do diário, ao atuar na produção da atenção, reconfigura a relação com o tema de pesquisa e mobiliza memórias relacionadas.

No presente artigo, nosso objetivo é discutir o papel do diário de campo na relação do(a) pesquisador(a) com o campo da pesquisa, tomando a abordagem metodológica da pesquisa-intervenção como contexto. Analisamos as narrativas escritas em diários de campo de pesquisadores(as) a respeito do seu agenciamento com tecnologias móveis em uma pesquisa que visava acompanhar processos de aprendizagem com um jogo de localização. A partir da perspectiva enativa da cognição (Varela, Thompson, \& Rosch, 2003), ampliamos a noção de campo-tema (Spink, 2008), discutindo a compreensão do afeto como um dos elementos centrais na modulação do acoplamento sujeito-mundo em contextos de pesquisa. Por fim, propomos que a escrita de diários de campo pode se constituir como uma estratégia de produção e análise da relação do(a) pesquisador(a) com o campo-tema da pesquisa, por meio da problematização da memória, do hábito e da produção de uma atenção focada na modulação da experiência de si e do mundo. 


\section{O Campo-Tema e os Afetos que Perpassam a Pesquisa}

A proposição de uma pesquisa-intervenção compreende a delimitação de um tema de pesquisa e a construção de uma estratégia metodológica que envolvem a produção de um contexto de experiência específico. É na interface entre esses elementos que emerge o campo empírico da pesquisa, não apenas como uma localidade geográfica, mas principalmente como um território existencial (Alvarez \& Passos, 2012) constituído das relações entre as práticas e os saberes de pesquisadores(as) e participantes da pesquisa.

Spink (2008) propõe a noção de campo-tema para questionar a compreensão do campo como atrelado a um local específico. De acordo com o autor, o campo-tema é a relação que o(a) pesquisador(a) estabelece com um assunto a ser estudado, desde o momento em que decide trabalhar com ele. A imersão do(a) pesquisador(a) no campo-tema da pesquisa pode ser mais central ou mais periférica - mais ou menos densa - dependendo da sua experiência em locais, em situações ou em conversas que colocam em movimento seu pensamento em relação ao tema estudado. Em todos esses casos, o(a) pesquisador(a) está se relacionando com seu problema de pesquisa. Não há, nessa perspectiva, uma hierarquia a priori entre os lugares e as interações formais ou informais em que se produz a pesquisa, sejam estes, por exemplo, discussões em reuniões do grupo de pesquisa, entrevistas com participantes ou conversas sobre o assunto no cotidiano.

Quando fazemos o que nós chamamos de pesquisa de campo, nós não estamos "indo" ao campo. Já estamos no campo, porque já estamos no tema. O que nós buscamos é nos localizar psicossocialmente e territorialmente mais perto das partes e lugares mais densos das múltiplas interseções e interfaces críticas do campo-tema onde as práticas discursivas se confrontem e, ao se confrontar, se tornam mais reconhecíveis (Spink, 2003, p. 36).

Uma vez que a configuração do campo da pesquisa se inicia com a relação do(a) pesquisador(a) com o tema pesquisado, sua extensão não pode ser reduzida ao espaço-tempo de realização de uma oficina ou entrevista. Quando tratamos de um campo-tema, pensar a implicação do(a) pesquisador(a) com a pesquisa na qual ele(a) está inserido compreende a produção de um posicionamento ético-político no pesquisar que, por sua vez, contribui para a problematização de outras formas de implicação em processos pessoais e profissionais no cotidiano. Pensar a implicação do(a) pesquisador(a) é reconhecer-se em um paradigma de 
pesquisa no qual os sentidos da intervenção são sempre problematizados e toda a ação de produção de conhecimento é entendida como intervenção no campo social. Neste sentido, é importante questionar os efeitos destas ações - realizar a análise das implicações - a partir da desnaturalização das dicotomias entre sujeito e objeto e manter vivas as tensões sempre presentes entre subjetividade e ciência (Paulon, 2005). O reconhecimento dessa produção que se dá a partir da ação incorporada do(a) pesquisador(a) amplia os espaços e possibilidades de produção de dispositivos de análise.

De acordo com Weber (2009) o diário de campo é uma ferramenta importante para a autoanálise do(a) pesquisador(a), não sendo um texto completo, mas um material de análise da pesquisa, podendo haver partes que não serão mencionadas em publicações científicas, mas que devem ser consideradas durante a análise dos dados. Os diários compreendem registros não somente de procedimentos técnicos, mas também conversas que "acontecem em filas de ônibus, no balcão da padaria, nos corredores das universidades; outras são mediadas por jornais, revistas, rádio e televisão" (Spink, 2003, p. 29). Esses lugares não são entendidos apenas como contextos que poderiam ser substituídos por outros, mas como espaços-tempo que compõem o processo de emergência do campo-tema da pesquisa. O que se diz em uma conversa em um bar é diferente do que se responde em uma entrevista na universidade, mas uma afirmação feita em uma situação não é mais verdadeira do que em outra, elas produzem modulações diferentes da pesquisa, por meio de diferentes inserções no campo-tema (Spink, 2003).

A abordagem enativa da cognição contribui para pensarmos o campo da pesquisa como performado pela produção de afetos, uma vez que estes determinam o que é relevante no mundo (Thompson, 2013). Ao participar da experiência perceptiva e mover a atenção, a afetação do(a) pesquisador(a) configura contornos para o campo-tema da pesquisa.

$\mathrm{O}$ afeto pode ser entendido como disposições corporais que determinam a cada momento quais eventos ou situações tornam-se relevantes, enquanto outros podem ser imperceptíveis, não fazendo parte da constituição do mundo para o sujeito (Thompson, 2013). Nesse sentido, há uma circularidade entre o processo afetivo que permite que um elemento se constitua como perturbação para o sujeito e o novo repertório de afetos que esta perturbação permite que sejam produzidos.

A escrita do diário de campo pode fazer parte do processo de imersão no campo-tema da pesquisa, não apenas configurar seu registro. Na relação com o campo-tema, a emergência de afetos aponta relevâncias, produz distinções que se destacam em um fundo como 
experiências a serem narradas. A escrita destas experiências pode produzir reflexões que levam ao surgimento de outros afetos, os quais disparam novas análises.

O afeto constitui nossa experiência corpórea e também se constitui como a efetivação da corporeidade. Antes de qualquer significado e qualquer modelo, somos um corpo imerso no mundo, aberto para os sentidos e sensações (Merleau-Ponty, 2006). Em outras palavras, somos afetados(as) segundo nossa corporeidade e os afetos constituem nossa forma incorporada de estar no mundo. A corporeidade se constitui como meio de produção de afetos e experiências compreendendo uma perspectiva epistemológica que atenta para as singularidades que emergem na relação entre pesquisador(a) e campo, performando a pesquisa. Assim, os afetos movimentam escolhas teórico-metodológicas, e por isso, uma pesquisa que propõe a discussão dos afetos como um de seus níveis de análise traz para o centro do debate as implicações éticas e políticas que o processo de pesquisar comporta, complexificando seus resultados.

\section{Metódo}

Este estudo foi desenvolvido tendo como objeto de análise os diários de campo de uma pesquisa que tinha por objetivo principal estudar processos de aprendizagem com um jogo digital de localização (Kroeff, 2016). O projeto de pesquisa do qual decorre o presente artigo foi aprovado pelo Comitê de Ética em Pesquisa o Instituto de Psicologia da Universidade Federal do Rio Grande do Sul (UFRGS) com número CAAE 53795616.5.0000.5334.

A tecnologia móvel necessária a estes jogos configura-se pela utilização de aparelhos portáteis - tablets, smartphones - conectados à internet para que os usuários possam acessar a rede estando em movimento. Nessa pesquisa, nossa hipótese principal era de que a imersão dos(as) jogadores(as) na cultura dos videogames contemplava aprendizagens relacionadas aos conteúdos narrativos dos jogos, assim como ao processo operativo de como aprender. Em outras palavras, que a experiência com os jogos digitais incluía o exercício constante de "aprender a aprender" como estratégia necessária para que o jogador desenvolvesse suas ações durante as partidas (Kroeff, 2016).

Participaram desta pesquisa adolescentes de 11 a 14 anos, estudantes do $4^{\circ}$ e $5^{\circ}$ ano de uma escola pública municipal localizada na cidade de Porto Alegre, RS. Foram realizados dois encontros entre os(as) adolescentes e o grupo de oficineiros(as) na escola. Esta etapa objetivou a aproximação com a tecnologia móvel utilizada na pesquisa (tablets). 
O jogo de localização "Um Dia no Jardim Botânico", utilizado na pesquisa, foi jogado em duplas pelos(as) participantes no Jardim Botânico de Porto Alegre, RS. As duplas foram compostas a partir do sorteio de um(a) estudante. Por sua vez, cada estudante sorteado(a) convidou um(a) colega com quem gostaria de jogar. Houve duplas somente de meninas ou de meninos e mistas, de acordo com a escolha dos(as) adolescentes. Realizamos cinco encontros de experiência de jogo no período de três meses, com a participação de 15 duplas e três casos nos quais adolescentes jogaram individualmente, somando 33 jogadores(as) (18 meninas e 15 meninos). Doze oficineiros(as) se revezaram participando dos encontros em datas distintas. Por oficina, cada dupla de jogadores(as) foi acompanhada por dois ou três integrantes do grupo de pesquisa. As duplas jogaram durante um período de, aproximadamente, duas horas e depois foi realizado um momento de conversa em grupo, no qual cada jogador(a) pôde compartilhar impressões, opiniões, estratégias de jogo e situações que foram experienciadas durante o jogo.

Considerando a metodologia de pesquisa-intervenção e com a proposta de discutir a relação entre os(as) pesquisadores(as) e a tecnologia estudada, foram realizados registros em diários de campo ao longo de todo o processo de elaboração e desenvolvimento da pesquisa. Os diários de campo incluíram a escrita de impressões gerais sobre os modos de interação com as tecnologias móveis. Os(as) pesquisadores(as) narravam cenas do cotidiano descrevendo a própria relação com a tecnologia estudada e também a de outras pessoas. Estes registros compreenderam, em especial, o movimento inicial de aproximação dos integrantes do grupo ao tema da pesquisa, a partir da análise de situações que contribuíram para a reflexão a respeito da implicação de cada um em relação às formas de utilização da tecnologia móvel. Os diários de campo foram escritos pelos(as) pesquisadores(as) e, posteriormente, compartilhados e discutidos coletivamente no grupo de pesquisa. A seguir, elegemos alguns trechos dos diários de campo, de modo a visibilizar diferentes formas de imersão no campotema da pesquisa.

\section{Resultados e Análise}

Conforme mencionamos anteriormente, a construção de uma questão a ser estudada já configura a inserção do(a) pesquisador(a) no campo-tema da pesquisa. O campo, portanto, não se restringe ao local e pode incluir aspectos da vida cotidiana dos(as) pesquisadores(as) (Spink, 2003). Alguns integrantes do grupo de pesquisa relataram em seus diários de campo como haviam se guiado no primeiro percurso até o local onde seria realizada uma das 
atividades com os(as) participantes da pesquisa. A chegada até a escola foi mais fácil do que achei que seria. Peguei [o ônibus] e fui acompanhando o caminho pelo Google Maps no smartphone, ajudada pelo motorista (Diário de campo 9). Se o usuário estiver com o sistema GPS de seu smartphone ou tablet ligado, é possível visualizar sua localização em relação ao destino desejado.

Para localizar a escola, realizei uma pesquisa no Google Maps. De carro, no local indicado pelo aplicativo, havia apenas residências de moradia. Por isso, eu e meu pai que me dava carona - pedimos informações e, depois de circular um grande canteiro de construções de prédios de alto porte, chegamos à escola (Diário de campo 11).

Esses exemplos envolvendo o percurso dos(as) pesquisadores(as) ao local da pesquisa demonstram que o campo não deve ser confundido com um local específico, mas é uma rede de relações das quais o(a) pesquisador(a) participa. Algumas experiências cotidianas passam a fazer parte da narrativa da pesquisa tanto quanto as produzidas no local escolhido. Nesse caso, os(as) pesquisadores(as) que se dirigiam para o local onde realizariam uma oficina sobre aplicativos de localização, utilizaram um aplicativo de localização para encontrar o local. Esse uso e a familiaridade dos(as) pesquisadores(as) com ele participou da produção da atividade.

A ação de pesquisar, contudo, também requer uma abertura à desterritorialização, ou seja, à possibilidade de que um saber estabelecido seja deslocado a partir de uma experiência na qual o(a) pesquisador(a) se deixa afetar e transformar (Marques \& Martino, 2017). Tomando a experiência do(a) pesquisador(a) como ponto de referência, compreendemos que a realização de uma pesquisa-intervenção atualiza modos de pensar-sentir-agir e que, como campo emergente de experiências, o movimento do pesquisar compreende uma abertura a diferentes temporalidades que se constituem na relação do(a) pesquisador(a) com o tema de pesquisa. Experiências anteriores podem adquirir um novo sentido mediante a emergência de questionamentos no momento presente.

Em 1996, aos onze anos, ganhei meu primeiro telefone celular. Tratava-se de um aparelho Nokia 2160 Monocromático que pesava mais do que qualquer outro artefato que eu carregasse na mochila da escola. Naquele ano, a professora de educação física do colégio me convidou para jogar voleibol no clube onde trabalhava no turno inverso às aulas. Por causa do horário de trabalho de minha mãe na época, ela não teria como me buscar no clube após os treinos. Assim, ela deixou que eu retornasse do clube de 
ônibus e me deu um celular para que pudesse falar comigo e saber que eu estava bem em qualquer parte do trajeto. O celular foi o passaporte para começar a jogar voleibol, atividade que pratiquei durante oito anos (Diário de campo 2).

Este relato demonstra como a característica móvel dos aparelhos celulares pode contribuir para a modulação de experiências cotidianas. Na narrativa acima, o uso deste dispositivo móvel permitiu uma ampliação do deslocamento pela cidade. A memória deste acontecimento ganhou nova relevância no processo de análise de implicação da pesquisadora, que refletiu a respeito de seu histórico de acoplamentos com a tecnologia e sobre a forma como isto envolvia modulações afetivas.

Segundo Marques e Biondi (2016), a experiência narrativizada - escrita e organizada sob a forma de um relato de si - nos transforma, possibilitando novas aberturas a afetações. A descrição da experiência narrada toma um novo sentido, uma nova perspectiva, cria-se uma diferença. Para estes autores tal experiência ganha forma - estética, política e ética - no gesto de "contar" e do "contar-se", constituindo um "processo transformador que culmina em uma outra forma de ser - ou em um vir a ser - e, por isso mesmo, elas promovem o confronto entre diferentes quadros de sentido, desencadeiam rupturas nos processos rotinizados" (Marques \& Biondi, 2016, p. 166). Há possibilidades de pequenos deslocamentos a partir da memória colocada em movimento.

O proposto por Marques e Biondi (2016) aproxima-se do que Maturana (2001) propõe sobre as explicações. Uma explicação, segundo Maturana (2001), é sempre uma experiência de reformulação de uma experiência anterior, ou seja, é uma experiência em si, não uma representação pura. A explicação não é apenas uma repetição, é a produção de uma experiência nova que existe a partir da memória de outra experiência. Neste processo de surgimento de uma nova experiência, se produz uma diferença em relação à experiência anterior, ou seja, no explicar podemos produzir algo novo a partir de nossas memórias. Assim, ao narrar a pesquisa no diário de campo, é possível um movimento da atenção do(a) pesquisador(a) e a produção de novas percepções e afetos.

Ao habitarmos um campo-tema, nossa relação com ele pode produzir novas explicações, criar uma nova perspectiva. Assim, nossa memória adquire novos sentidos em consonância com os afetos do campo-tema no momento presente. No exemplo do diário de campo acima se produziu uma nova explicação, que liga a tecnologia móvel à forma de habitar a cidade, em conexão com o campo-tema da pesquisa que abordava as tecnologias digitais. 
Spink (2008) sugere que é um desafio do(a) pesquisador(a) aprender a dar atenção ao cotidiano, tornando a pesquisa parte dele. Não se trata de trabalhar constantemente, mas de uma abertura atencional a elementos que possam integrar o campo-tema como território existencial. A partir do exemplo a seguir, observamos que a pesquisadora desenvolve uma atenção sensível à relação entre o hábito, a percepção da passagem do tempo e a tecnologia móvel.

Meu namorado esqueceu seu smartphone em casa. Mais tarde, utilizando um computador em seu trabalho, ele trocou mensagens comigo e marcamos de nos encontrar em um bar algumas horas depois. Antes de sair do trabalho, ele me enviou uma última mensagem dizendo que estava a caminho do lugar combinado, mas eu só vi a mensagem quando ele já havia desconectado. Ele chegou antes no lugar combinado. Me contou que escolheu uma mesa e, enquanto esperava ansiosamente olhando para a porta, ficou se perguntando se teria ocorrido algum imprevisto que me impedisse de ir até lá encontrá-lo, se eu teria necessitado entrar em contato nestes pouco mais de 30 minutos após ele ter saído de frente de seu computador no trabalho e o que ele faria se eu demorasse muito tempo para chegar. Seus pensamentos foram interrompidos por minha chegada. Nenhum de nós possuía relógio de pulso, mas no relógio presente no visor do meu celular verificamos que eu ainda havia chegado cinco minutos antes do horário combinado (Diário de campo 3).

A relação estabelecida com uma tecnologia que associa mobilidade e comunicação produz ao mesmo tempo um meio informacional no qual há a sensação de poder falar com o outro sempre que desejável e um sujeito habituado a agir a partir deste agenciamento. A experiência de ir a um encontro sem a possibilidade de se comunicar com a pessoa durante o percurso de deslocamento tornou-se uma situação bastante incomum em uma cultura de conexão constante à internet. A inserção no campo-tema de uma pesquisa sobre a tecnologia móvel produziu a transformação da experiência de interrupção da comunicação em objeto de análise. $\mathrm{O}$ que em outros momentos poderia ser vivenciado apenas como uma eventualidade momentânea desagradável, possibilitou a problematização dos efeitos da tecnologia na percepção do tempo e espaço. Desse modo, não apenas elementos do cotidiano transformam a pesquisa, mas também o contrário. Pode acontecer do(a) pesquisador(a) experienciar o cotidiano de uma forma diferente a partir da implicação com o tema da pesquisa. Tomar o campo como campo-tema produz uma relação do(a) pesquisador(a) com a pesquisa de forma 
implicada, o que produz reverberações na vida cotidiana. A participação na pesquisa modifica a relação com o cotidiano, faz com que se possa perceber de outros modos, produzindo um olhar problematizador. Existe, então, uma relação de coemergência entre a experiência do cotidiano e o campo-tema da pesquisa. No exemplo a seguir, podemos observar uma outra modulação desse processo de coprodução.

Eu falei para um amigo que estávamos estudando sobre jogos para jogar no celular e tablets que usavam sistema GPS e ele me falou do Ingress. Eu fiquei curiosa e resolvi baixar para jogar. Escolhi ser da Resistência, porque então poderia competir com o meu amigo que é Enlightened. Descobri que perto de casa haviam dois portais. Fazendo um percurso um pouco diferente para chegar em casa, aproveitei para ir até um deles. Era um portal Enlightened. [...]. Tenho aproveitado para conectar o Ingress quando estou andando pela cidade. Já descobri vários outros portais perto de lugares que costumo ir recorrentemente. Consegui ganhar alguns itens e aumentar de nível (Diário de campo 6).

O jogo Ingress é um exemplo de jogo baseado em localização que mistura características de MMO (Massive Multiplayer Online) com realidade aumentada. Ao falar sobre a experiência com o jogo Ingress, a integrante do grupo de pesquisa diz que começou a jogar por curiosidade, a partir da indicação de amigos(as), pois o jogo se baseava em tecnologia móvel de localização. Ela descobre a localização de vários portais em poucas semanas, conectando-se ao jogo através de seu celular durante caminhos cotidianos, como no trajeto entre sua casa e a universidade ou as idas ao supermercado, casas de amigos(as), etc. Algumas vezes, experimenta modificações nos percursos que faz para tentar descobrir novos portais ou voltar a acessar portais em localizações já conhecidas. Dessa forma, a partir da relação com o jogo, ela vivencia a descoberta de novos caminhos entre pontos de partidas e chegadas, explorando territórios novos e conhecidos não apenas digitalmente, mas também fisicamente. Assim, a inserção da pesquisadora no campo-tema modificou a forma como ela agia no cotidiano, incluindo a conversa com um amigo, conforme descrito no diário. Essa modificação leva a uma mudança no modo como ela se coloca no campo-tema, nesse caso experimentando um novo jogo, que por sua vez, volta a transformar o cotidiano da pesquisadora, produzindo novas formas de ela se deslocar pela cidade.

$\mathrm{Na}$ pesquisa-intervenção a escrita de diários de campo é orientada a descrever processos mais do que estados de coisas (Passos \& Eirado, 2012). Em outras palavras, nas 
narrativas que abordamos em nossa análise importava descrever os usos que os(as) pesquisadores(as) faziam da tecnologia e desnaturalizar o modo como sua presença modulava práticas e relações sociais.

A escrita faz parte do saber-fazer do(a) pesquisador(a). O diário de campo não é um texto pronto, como um resultado final da pesquisa, mas está inserido no procedimento metodológico. A forma como nos inserimos no campo-tema modula o percurso, que vai se constituindo desde a proposta da questão a ser estudada até a finalização da pesquisa. Como uma complexa rede de sentidos que se interconectam, o campo-tema envolve negociações. A dimensão do afeto compõe as relações do campo e, por isso, deve ser pensada como questão metodológica, ao questionarmos o processo de conhecer.

Em uma pesquisa-intervenção, a construção de um método de pesquisa não se configura como uma estratégia para desvelar uma verdade sobre um local ou grupo, e sim uma maneira de participar da discussão de uma realidade produzida intersubjetivamente e a partir de uma rede complexa de seres vivos, objetos, instituições e tecnologias, entre outros elementos na pesquisa. Por isso, a construção da estratégia metodológica não se restringe a elaborar e obedecer a orientações, mas abrange também a relação com o campo de estudo e, desta forma, não podemos deixar de considerar que em cada versão metodológica se efetua um plano de afetos singular.

\section{Considerações Finais}

Abordar a noção de afeto, em uma perspectiva enativa, nos possibilita refletir sobre a experiência corporal do ser no mundo, que compreende as dimensões biológica, psicológica e sociocultural. Acreditamos que discutir a relação dos(as) pesquisadores(as) com seu objeto de estudo (entendido aqui como campo-tema) é uma forma de provocar a visibilidade de produção de afetos e saberes que compõem o campo da pesquisa muitas vezes de forma implícita.

Para pensar a questão do afeto como modulador de sentido no pesquisar, tomamos como estratégia metodológica a análise de diários de campo escritos em uma pesquisa sobre tecnologias móveis. Cabe a problematização a respeito de uma leitura individualista que pode ser feita do papel dos diários de campo, como se eles fossem um registro intimista do(a) pesquisador(a), em sua atuação como autor(a) em um contexto de subjetivação neoliberal. Propomos que a produção de uma escrita reflexiva não tenha por objetivo ser um registro intimista do(a) pesquisador(a), pois envolve um conjunto de eventos e afetos que se dão a 
partir da participação de coletivos diversos implicados em um campo-tema. Como forma de tensionar para que seja uma escrita singular, e não individualista, apostamos na discussão coletiva das produções de diário e da análise dos seus elementos também a partir do que se produz como coletivo de pesquisadores(as), que é diferente do que seria produzido em uma pesquisa solitária. A ferramenta de análise das implicações, nesse aspecto, é de fundamental importância, assim como ressaltar que aquilo que cada pesquisador(a) registra no diário é também efeito da formulação dos objetivos e pressupostos que norteiam a pesquisa, não sendo uma produção ocasional ou neutra.

A escrita de cada diário de campo possui endereçamentos, à medida que será um texto compartilhado com outros integrantes da pesquisa e que alguns trechos, possivelmente, constituam parte da escrita de publicações para outros(as) pesquisadores(as) e/ou profissionais. Desta forma, nenhum diário de campo irá contemplar o registro de uma suposta totalidade da experiência de pesquisa, pois é um texto organizado, editado e apurado conforme propósitos narrativos específicos, o que pode implicar movimentos de censura (mesmo que não propositais). É importante termos isto em vista, a fim de que a problematização das escolhas narrativas e a consideração das possíveis limitações da escrita presentes nos diários de campo sejam parte integrante do trabalho de pesquisa.

Situando o diário de campo na modulação da atenção do(a) pesquisador(a), consideramos o seu caráter "inacabado", no sentido de que pode seguir passando por transformações. Em alguns momentos, o(a) pesquisador(a) atenta para uma situação do cotidiano sem que necessariamente faça no momento uma formulação explicativa-teórica, mas a imersão no campo-tema permite que a atenção se volte a cenas que são narradas e no operar da pesquisa ganham relevância para novas explicações.

Conforme discutimos até aqui, uma escrita de diários de campo que abranja não somente o que é consolidado como o "campo empírico" da pesquisa, mas também a relação do(a) pesquisador(a) com o tema de estudo pode potencializar estratégias de pesquisaintervenção. Neste sentido, nos desafiamos a colocar em análise nosso posicionamento éticopolítico de relação com os(as) participantes, o assunto e as instituições implicadas na pesquisa no cotidiano. Os movimentos atencionais dos(as) pesquisadores(as), tomados aqui como elemento central na modulação da pesquisa, podem ser acompanhados através das narrativas presentes no diário, de modo que a observação crítica dos elementos do cotidiano que vão ganhando relevância pode efetuar transformações não somente na atenção dos(as) pesquisadores(as), mas também nas possibilidades de invenção e do desenvolvimento da 
pesquisa. Assim, a proposta ético-política na produção de diários constitui uma aposta na coprodução entre pesquisador(a), participantes, interlocutores(as) e objeto de estudo.

O conceito de campo-tema, além de ser um guia para a produção de diários de campo, pode influenciar o fazer ético da pesquisa-intervenção, na forma de conduzir a relação com os(as) participantes da pesquisa. Considerando que os(as) participantes atuam ativamente na produção de modulações do campo-tema, podemos incluir formas de participação em diferentes momentos do desenvolvimento da pesquisa. Um exemplo na pesquisa citada neste artigo foi a inclusão de uma roda de conversa com os(as) participantes ao final de cada oficina, a fim de que eles(as) pudessem contribuir na discussão e análise da experiência. Embora este não seja o enfoque principal da nossa discussão, trata-se de um direcionamento ético que também modula os resultados de uma pesquisa a partir da noção de campo-tema.

\section{Referências}

Aguiar, K. F., \& Rocha, M. L. (1997). Práticas universitárias e a formação sócio-política. Anuário do Laboratório de Subjetividade e Política, 3(4), 87-102. Recuperado de https://www.acheronta.org/acheronta11/socio-politica-p.htm

Alvarez, J., \& Passos, E. (2012). Cartografar é habitar um território existencial. In E. Passos, V. Kastrup, \& L. Escóssia (Orgs.), Pistas do método da cartografia: Pesquisaintervenção e produção de subjetividade (pp. 131-149). Porto Alegre: Sulina.

Kastrup, V. (2012). O funcionamento da atenção no trabalho do cartógrafo. In E. Passos, V. Kastrup, \& L. Escóssia (Orgs.), Pistas do método da cartografia: Pesquisaintervenção e produção de subjetividade (pp. 32-51). Porto Alegre: Sulina.

Kroeff, R. F. S. (2016). Experiências coletivas com tecnologias digitais: Um encontro entre videogames e a cultura da mobilidade (Dissertação de mestrado). Universidade Federal do Rio Grande do Sul, Porto Alegre, RS, Brasil. Recuperado de http://hdl.handle.net/10183/141039

Marques, A., \& Biondi, A. (2016). A vítima enunciada em redes: O dissenso como experiência estética. In C. M. C. Mendonça, E. Duarte, \& J. Cardoso Filho (Orgs.), Comunicação e sensibilidade: Pistas metodológicas (pp. 165-188). Belo Horizonte: PPGCOM UFMG.

Marques, A. C. S., \& Martino, L. M. S. (2017). Afetividades e vulnerabilidades na relação pesquisador/sujeito pesquisado. In D. A. Künsch, E. Dias, M. Y. Passos, P. E. 
Fernandes, P. Torres, \& D. Brito (Orgs.), Produção de conhecimento e compreensão (pp. 37-50). São Paulo: UNI.

Maturana, H. (2001). Cognição, Ciência e Vida Cotidiana. Belo Horizonte: UFMG.

Merleau-Ponty, M. (2006). Fenomenologia da percepção. São Paulo: Martins Fontes.

Oliveira, R. D. C. M. (2014). (Entre) Linhas de uma pesquisa: O Diário de Campo como dispositivo de (in)formação na/da abordagem (Auto)biográfica. Revista Brasileira de Educação de Jovens e Adultos, 2(4), 69-87. Recuperado de: https://www.revistas.uneb.br/index.php/educajovenseadultos/article/view/1059/730

Passos, E., \& Barros, R. B. (2012). Por uma política da narratividade. In E. Passos, V. Kastrup, \& L. Escóssia (Orgs.), Pistas do método da cartografia: Pesquisaintervenção e produção de subjetividade (pp. 150-171). Porto Alegre: Sulina.

Passos, E., \& Eirado, A. (2012). Cartografia como dissolução do ponto de vista do observador. In E. Passos, V. Kastrup, \& L. Escóssia (Orgs.), Pistas do método da cartografia: Pesquisa-intervenção e produção de subjetividade (pp. 109-130). Porto Alegre: Sulina.

Passos, E., Kastrup, V., \& Escóssia, L. (2012). Pistas do método da cartografia: Pesquisaintervenção e produção de subjetividade. Porto Alegre: Sulina.

Paulon, S. M. (2005). A análise de implicação como ferramenta na pesquisa-intervenção. Psicologia \& sociedade, 17(3), 18-25. Recuperado de http://www.scielo.br/pdf/psoc/v17n3/a03v17n3.pdf

Pezzato, L. M., \& L'abbate, S. (2011). O uso de diários como ferramenta de intervenção da Análise Institucional: Potencializando reflexões no cotidiano da Saúde Bucal Coletiva. Physis: Revista de Saúde Coletiva, 21(4), 1297-1314. doi:10.1590/S010373312011000400008

Rocha, M. L., \& Aguiar, K. F. (2003). Pesquisa-intervenção e a produção de novas análises. Psicologia: Ciência e profissão, 23(4), 64-73. doi:10.1590/S141498932003000400010

Spink, P. K. (2008). O pesquisador conversador no cotidiano. Psicologia \& Sociedade, 20(spe), 70-77. doi:10.1590/S0102-71822008000400010

Spink, P. K. (2003). Pesquisa de campo em psicologia social: Uma perspectiva pósconstrucionista. Psicologia \& Sociedade, 15(2), 18-42. doi:10.1590/S010271822003000200003

Thompson, E. (2013). A mente na vida: Biologia, Fenomenologia e Ciências da Mente. Lisboa: Instituto Piaget. 
Varela, F. J., Thompson, E., \& Rosch, E. (2003). A mente incorporada. Porto Alegre: Artmed. Weber, F. (2009). A entrevista, a pesquisa e o íntimo, ou por que censurar seu diário de campo?. Horizontes Antropológicos, 15(32), 157-170. doi:10.1590/S010471832009000200007

\section{Endereço para correspondência}

\section{Renata Fischer da Silveira Kroeff}

Rua Ramiro Barcelos, 2600 sala 400e, Santa Cecília, Porto Alegre - RS, Brasil. CEP 90035-003

Endereço eletrônico: kroeff.re@gmail.com

\section{Póti Quartiero Gavillon}

Rua Ramiro Barcelos, 2600 sala 400e, Santa Cecília, Porto Alegre - RS, Brasil. CEP 90035-003

Endereço eletrônico: poti.gav@gmail.com

\section{Laís Vargas Ramm}

Rua Ramiro Barcelos, 2600 sala 400e, Santa Cecília, Porto Alegre - RS, Brasil. CEP 90035-003

Endereço eletrônico: laisramm@gmail.com

Recebido em: 26/11/2019

Reformulado em: 02/03/2020

Aceito em: 17/04/2020

\section{Notas}

* Doutoranda em Psicologia Social e Institucional (UFRGS). Mestra em Psicologia Social e Institucional (UFRGS). Psicóloga (UNISINOS).

** Doutor em Psicologia Social e Institucional (UFRGS). Mestre em Psicologia Social e Institucional (UFRGS). Psicólogo (UFRGS).

*** Doutoranda em Informática na Educação (UFRGS). Mestra em Psicologia Social e Institucional (UFRGS). Psicóloga (UFPel).

Financiamento: A pesquisa relatada no manuscrito foi financiada pela bolsa de mestrado da primeira autora (CAPES).

Este artigo de revista Estudos e Pesquisas em Psicologia é licenciado sob uma Licença Creative Commons Atribuição-Não Comercial 3.0 Não Adaptada. 